\title{
Relation between the characteristics of strong earthquake activities in Chinese mainland and the Wenchuan earthquake*
}

\author{
Xiaodong Zhang ${ }^{1, \star}$ Guohua Yang ${ }^{2} \quad$ Xian $\mathrm{Lu}^{1}$ \\ Mingxiao $\mathrm{Li}^{1}$ and Zhigao Yang ${ }^{1}$ \\ ${ }^{1}$ China Earthquake Networks Center, Beijing 100045, China \\ ${ }^{2}$ First Crustal Deformation Monitor and Observation Center, China Earthquake Administration, Tianjin 300180, China
}

\begin{abstract}
This paper studies the relations between the great Wenchuan earthquake and the active-quiet periodic characteristics of strong earthquakes, the rhythmic feature of great earthquakes, and the grouped spatial distribution of $M_{\mathrm{S}} 8.0$ earthquakes in Chinese mainland. We also studied the relation between the Wenchuan earthquake and the stepwise migration characteristics of $M_{\mathrm{S}} \geq 7.0$ earthquakes on the North-South seismic belt, the features of the energy releasing acceleration in the active crustal blocks related to the Wenchuan earthquake and the relation between the Wenchuan earthquake and the so called second-arc fault zone. The results can be summarized as follows: (1) the occurrence of the Wenchuan earthquake was consistent with the activequiet periodic characteristics of strong earthquakes; (2) its occurrence is consistent with the features of grouped occurrence of $M_{\mathrm{S}} 8.0$ earthquakes and follows the 25 years rhythm (each circulation experiences the same time) of great earthquakes; (3) the Wenchuan $M_{\mathrm{S}} 8.0$ earthquake follows the well known stepwise migration feature of strong earthquakes on the North-South seismic belt; (4) the location where the Wenchuan $M_{\mathrm{S}} 8.0$ earthquake took place has an obvious consistency with the temporal and spatial characteristic of grouped activity of $M_{\mathrm{S}} \geq 7.0$ strong earthquakes on the second-arc fault zone; (5) the second-arc fault zone is not only the lower boundary for earthquakes with more than $30 \mathrm{~km}$ focal depth, but also looks like a lower boundary for deep substance movement; and (6) there are obvious seismic accelerations nearby the Qaidam and Qiangtang active crustal blocks (the northern and southern neighbors of the Bayan Har active block, respectively), which agrees with the GPS observation data.
\end{abstract}

Key words: characteristic of $M_{\mathrm{S}} 8.0$ earthquakes; Wenchuan earthquake; second arc fault zone CLC number: P315.5 Document code: A

\section{Introduction}

A devastating earthquake with $M_{\mathrm{S}} 8.0$ occurred in Wenchuan county, Sichuan province, at 14:28 on May 12, 2008, which causes a lot of people's life and huge economic losses. According to the governmental official report, more than 69000 people were killed, at least 18000 were missing and more than 8000 billion RMB Yuan of direct economic losses. The occurrence of such a great catastrophic earthquake has attracted many experts and scholars from different disciplines of China and abroad to thoroughly study the Wenchuan earthquake. Among them, the relation between the Wenchuan earthquake

\footnotetext{
* Received 24 March 2009; accepted in revised form 18 August 2009; published 10 October 2009 .

Corresponding author.e-mail: zxd@seis.ac.cn
}

$\left(M_{\mathrm{S}} 8.0\right)$ and the characteristics of earthquake activity in Chinese mainland still remains questionable. Therefore, it is important to give a reasonable explanation to the above relation. On the other hand, it is also necessary to review and investigate the Wenchuan earthquake due to the underestimation on the risk before the quake.

Generally speaking, big earthquakes are relatively small probabilistic events during the long history so that it is important and also necessary to fully review and thoroughly investigate the mechanism and the precursor (or anomaly) after the big earthquake. In recent years, a series of great shocks occurred worldwide. After each of them, scientists always thoroughly study and investigate the causes and mechanism, including the characteristics of earthquake activities and precursory anomalies. For example, Wiemer and Wyss (1994) studied the quiescence phenomena before the Landers $M_{\mathrm{W}} 7.3$ earthquake 
occurred on June 28, 1992 in Landers, USA and its strong aftershocks; Hauksson (1994) discussed the stress level in the Landers area by analyzing the focal mechanisms of quake series before and after the Landers earthquake; Frank et al (1994) investigated the variations of continuous crustal deformation observed before and after the Landers earthquake; Dodge et al (1995) and Bouchon et al (1998a) established the relation between the nucleation phenomenon of the Landers earthquake and the stress state and seismic fracture; Bouchon et al (1998b) discussed the characteristics of the stress field in the Hanshin M7.2 earthquake (on January 17, 1995 in Hanshin, Japan); Chen et al (2006) investigated the correlated and cooperative behavior on Hanshin earthquake fault systems using the critical point theory; Iio et al (2002) and Aktar et al (2004) studied the aftershocks' spatial distribution of the Turkey $M 7.8$ earthquake on August 17, 1999; Negishi et al (2002) investigated the fault scale and fracture orientation using the observed Gujarat aftershock sequence (the Gujarat main shock occurred on January 26, 2001 in Gujarat area, India with magnitude of M7.8); Charles (2004) and Walker and Shearer (2009) compared western Kunlun mountain pass earthquake (on November 14, 2001, in Kunlun mountain region with magnitude of M8.1) and Denali earthquake (on November 3, 2001 in Alaska, USA with magnitude of M8.5); Chao and Gross (2005) studied the effect of the Indonesia huge earthquake (on December 26, 2004 in Indonesia with magnitude of M9.0) on the Earth's rotation; Kondo et al (2008) studied the long-term recurrence interval of Pakistan earthquake (on October 8, 2005 in Pakistan with magnitude of $M 7.8$ ) in the Kashmir seismogenic region; Parsons et al (2008) investigated the change of stress field in Wenchuan earthquake source region; Zhao et al (2008) analyzed the preseismic density variations of the ionosphere. Such huge research reports related to the mechanism, the cause and precursory characteristic before and after the big earthquake can not be fully included here due to the space limitation.

After the occurrence of a large earthquake, researchists would first ask whether anomalous phenomena appear before the quake or not. Some phenomena would be attributed to other factors if the Wenchuan earthquake did not occur, but now such phenomena seem to be connected directly to the Wenchuan earthquake. Nevertheless, it is still difficult for us to make a decision with greater certainty if the similar phenomena appear in the future. In spite of this, such kind of re- search and investigation can still promote the development of earthquake science. This paper gives a comprehensive analysis of the anomalous phenomena before and after the Wenchuan earthquake, though it may not be fully accountable, but it is really a good start. Here we will examine and analyze the abnormal phenomena prior to the great Wenchuan earthquake.

\section{Time characteristics of strong seismic activity in China}

First of all, it is important to study the characteristics of seismic activity in Chinese mainland so as to fully understand the background of Wenchuan earthquake. Secondly, it is also necessary to investigate the characteristics of seismic activity on the well known North-South seismic belt due to the location of the Wenchuan earthquake and its tectonic relationship. Thirdly, it is equally important to discuss the seismic characteristics of Bayan Har active block, which is the western margin of the Longmenshan fault zone.

\subsection{Active-quiet characteristics of strong earth- quakes in Chinese mainland versus the Wenchuan earthquake}

The $M_{\mathrm{S}} \geq 7.0$ earthquakes in Chinese mainland are of very obvious active and quiet alternative characteristics (Fu and Cheng, 1986). It has been acknowledged that the periodic phases of 1889-1911, 1920-1937, 1947-1955, and 1966-1976 are active phases of $M_{\mathrm{S}} \geq 7.0$ earthquakes; while the time intervals between nearby active phases, i.e., 1912-1919, 1938-1946, 1956-1965 and 1977-1987, are quiet phases of $M_{\mathrm{S}} \geq 7.0$ earthquakes. Note that the above so-called quiet phases do not mean that there are no $M \geq 7.0$ earthquakes occurred, but with a longer time interval and lower energy release instead. In the active phase of $M_{\mathrm{S}} 7.0$ earthquakes, $M_{\mathrm{S}} \geq 7.0$ earthquakes are not only of higher frequency, but also of higher intensity. Up to the present, we are still unable to ascertain whether the last active phase started in 1988 has ended or not; if it does, when it is ended? Some experts insist on that western Kunlun mountain pass earthquake (on November 14, 2001) marks the termination of the last active phase of $M_{\mathrm{S}} \geq 7.0$ earthquakes; others hold that the Wenchuan M8.0 earthquake (on May 12, 2008 ) is the termination index. Besides above two point views, other experts believe that the last seismic active phase, which started at 1988 , has some characteristics quite different from those of the past active phases, and hence the seismic active and quiet phases can hardly be 
distinguished. Thus the hypothesis of seismic active and quiet phases is questionable and faces a big challenge (Liu et al, 2008, 2009; Chen and Li, 2008, 2009). In this paper, it is considered that the time interval of 1988-2001 is a seismic active phase, 2002-2007 is a relatively short seismic quiet phase, and 2008 is the beginning of a new seismic active phase. This point of view will be further expounded later on when discussing the time characteristics of strong earthquake activity on the North-South seismic belt. What is more, question marks are added in the second and last rows in Table 1, which shows that there is still controversy and a final conclusion is unable to make. Figure $1 \mathrm{a}$ is the $M$ - $t$ diagram of $M_{\mathrm{S}} \geq 7.0$ earthquakes occurred in Chinese mainland since 1900 . Figure $1 \mathrm{~b}$ gives the time lags between two consecutive $M_{\mathrm{S}} \geq 7.0$ earthquakes, which shows that there are seven longer time separations that lasted over three and half years (or 1280 days). The $M_{\mathrm{S}} \geq 7.0$ earthquakes followed by a longer quiet time are listed in Table 1. It can be seen from the diagram that the long-time quiescence of $M_{\mathrm{S}} \geq 7.0$ earthquakes was generally broken by events of $M_{\mathrm{S}} 7.0$ or $M_{\mathrm{S}} 7.1$, seldom by stronger events with two exceptions given below. One is the Fuyun $M_{\mathrm{S}} 8.0$ earthquake (on August 11, 1931 in Fuyun county, Xinjiang) which broke the quiescence that lasted three years and three months after the Gulang $M_{\mathrm{S}} 8.0$ earthquake (on May 23, 1927 in Gulang county, Gansu province); the other is the Kunlun $M_{\mathrm{S}} 8.1$ earthquake (on November 14, 2001 in Kunlun mountain), which broke the four years' quiescence after the Mani $M_{\mathrm{S}} 7.5$ earthquake (on November 8, 1997 in Tibet). Examination of the quiet and active phases of seismic activity in Chinese mainland shows that if the longer time quiescence appeared at the end or beginning of an active phase, the earthquake that broke the calm is always with magnitude of $M_{\mathrm{S}} 7.0$ or $M_{\mathrm{S}} 7.1$. For example, the time interval between the Qilin Lake $M_{\mathrm{S}} 7.0$ earthquake (on August 20, 1908 in Tibet) and the E'shan $M_{\mathrm{S}} 7.0$ earthquake (on December 21, 1913 in Yunnan) is five years and four months, the Heze $M_{\mathrm{S}} 7.0$ earthquake (on August 1,1937 in Shandong) and the Gengma $M_{\mathrm{S}} 7.0$ earthquake (on May 16, 1941 in Yunnan) is four years and nine months, the Kangding $M_{\mathrm{S}} 7.5$ earthquake (on April 14, 1955 in Sichuan) and the Alan Lake $M_{\mathrm{S}} 7.0$ earthquake (on April 19, 1963 in Qinghai) is eight years and the north Pingwu $M_{\mathrm{S}} 7.2$ earthquake (on August 23, 1976 in Sichuan) and the Wuqia $M_{\mathrm{S}} 7.1$ quake (on August 23, 1985 in Xinjiang) is nine years.
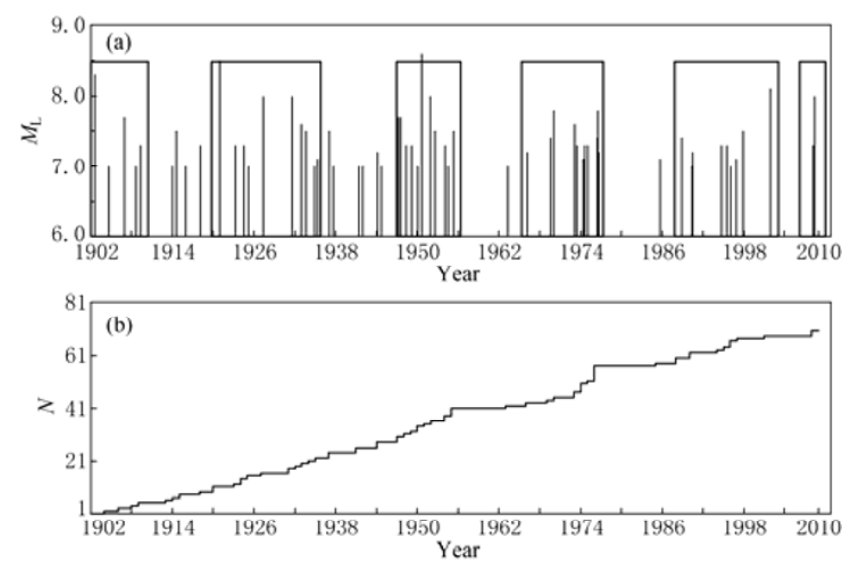

Figure 1 Time characteristics of $M_{\mathrm{S}} \geq 7$ earthquakes in Chinese mainland. (a) $M$ - $t$ diagram where the rectangles indicate seismic active phases and others are seismic quiet phases; (b) Accumulative frequency $(N)$ curve.

Table 1 Statistics of long-time quiescence of $M_{\mathrm{S}} 7.0$ earthquakes in Chinese mainland

\begin{tabular}{|c|c|c|c|c|c|c|c|c|c|c|}
\hline \multirow{2}{*}{ No. } & \multirow{2}{*}{\multicolumn{2}{|c|}{$\begin{array}{l}\text { Result of quiet and } \\
\text { active phases division }\end{array}$}} & \multicolumn{3}{|c|}{ Indicated quake for beginning of the quiet phase } & \multicolumn{3}{|c|}{ Indicated quake for ending of the quiet phase } & \multirow{2}{*}{$\begin{array}{l}\text { Quiet time } \\
\qquad / \mathrm{mo}\end{array}$} & \multirow{2}{*}{ State } \\
\hline & & & a-mo-d & Location & $M_{\mathrm{S}}$ & a-mo-d & Location & $M_{\mathrm{S}}$ & & \\
\hline 1 & $1912-1919$ & Quiet phase & $1908-08-20$ & Qilin Lake, Tibet & 7.0 & $1913-12-21$ & E'shan, Yunnan & 7.0 & 64 & Quiet \\
\hline 2 & $1920-1937$ & Active phase & $1927-05-23$ & Gulang, Gansu & 8.0 & 1931-08-11 & Fuyun, Xinjiang & 8.0 & 39 & Active \\
\hline 3 & $1938-1946$ & Quiet phase & 1937-08-01 & Heze, Shandong & 7.0 & $1941-05-16$ & Gengma, Yunnan & 7.0 & 57 & Quiet \\
\hline 4 & $1956-1965$ & Quiet phase & 1955-04-14 & Kangding, Sichuan & 7.5 & 1963-04-19 & Alan Lake, Qinghai & 7.0 & 96 & Quiet \\
\hline 5 & $1977-1987$ & Quiet phase & $1976-08-23$ & Pingwu, Sichuan & 7.2 & $1985-08-23$ & Wuqia, Xinjiang & 7.1 & 108 & Quiet \\
\hline 6 & 1988-2001 & Active phase? & 1997-11-08 & Mani, Tibet & 7.5 & 2001-11-04 & Kunlun mountain & 8.1 & 48 & Active? \\
\hline 7 & 2008-? & Active phase? & 2001-11-14 & Kunlun mountain & 8.1 & $2008-05-12$ & Wenchuan, Sichuan & 8.0 & 42 & Active? \\
\hline
\end{tabular}

Note: Question marks in the table represent uncertainty.

Between the Kunlun mountain $M_{\mathrm{S}} 8.1$ of 2001 and the Wenchuan $M_{\mathrm{S}} 8.0$ earthquake of $2008, M_{\mathrm{S}} \geq 7.0$ earthquakes in Chinese mainland had kept quiet for more than six years. At that time, it was inferred from the active-quiet pattern of historical earthquakes that the longer the quiet phase, the higher the probability for $M_{\mathrm{S}} \geq 7.0$ earthquake; but the first-strike earthquake would not be too big, possibly with the magnitude of $M_{\mathrm{S}} 7.0-7.1$, at most not higher than $M_{\mathrm{S}} 7.5$. In earthquake history, there is the case that the seismic quiet phase 
lasted eight or nine years. From this evidence, it is possible that the quiet phase can last even a longer time, say, two or three more years than that of the above long quiet time is still reasonable. Based on the above consideration, we predicted that the earthquake activity would be in the level of $M_{\mathrm{S}} 6.0-7.0$. That is to say that earthquake with magnitude around $M_{\mathrm{S}} 7.0$ may be possible, but events greater than $M_{\mathrm{S}} 7.5$ would be unlikely to occur in the annual consultation before the Wenchuan $M_{\mathrm{S}} 8.0$ earthquake. Now, we underestimated the annual trend of earthquake activity in Chinese mainland. In the above meeting, some scientific researchers on earthquake prediction considered that this seismic quiet time $\left(M_{\mathrm{S}} \geq 7.0\right)$ may last eight or nine years, especially after the occurrence of western Kunlun mountain pass $M_{\mathrm{S}} 8.1$ earthquake. This is also one of the reasons why the active level of earthquake in Chinese mainland was judged to be $M_{\mathrm{S}} 6.0-7.0$ in that time (Liu et al, 2008). In present point of view, the classification of seismic active-quiet patterns is not a rigorous criterion but an approximation; a strictly mathematical classification is nonsense. It may be a nonlinear behavior belonging to a huge complex system. Once a long-term quiescence appears, it may be a signal for system transformation, but a very effective way to judge when the system changes is still lacking. In such a case, uncertainties should be considered in the annual trend prediction. According to the situation of that time, it would be appropriate to make a judgment for earthquake trend with magnitude around $M_{\mathrm{S}} 7.0$, not $M_{\mathrm{S}} 6.0-7.0$ level, which obviously did not take into consideration of the system uncertainty.

2.2 Time characteristicsof strong earthquake activity on the North-South seismic belt

Strong earthquakes occurred in the region of $20^{\circ} \mathrm{N}-$ $45^{\circ} \mathrm{N}, 95^{\circ} \mathrm{E}-107^{\circ} \mathrm{E}$, especially disastrous earthquakes. This region is an earthquake-prone zone. It is a gradient belt of landform and gravity variation, and really an active belt of geological structures in Chinese mainland. Besides, it is also a transitional zone from the eastern densely populated region to the western sparsely inhabited region. Therefore, once strong earthquakes take place in this region, the induced secondary disasters (landform collapse, landslide, mud-rock flow, etc) would be very serious, with heavy casualties of human life. This region is located at the eastern margin of Qinghai-Tibet plateau and is called the North-South seismic belt.

Figure 2 is the $M$ - $t$ diagram of earthquakes with $M_{\mathrm{S}} \geq 7.0$ on the North-South seismic belt from the Chinese earthquake catalog (earthquake monthly report of China Earthquake Networks Center) after 1900. It can be seen obviously that $M_{\mathrm{S}} \geq 7.0$ earthquakes on this belt have the alternative characteristics of active-quiet pattern. There had been four active phases for $M_{\mathrm{S}} \geq 7.0$ earthquakes. The first one started on December 16, 1920 (Haiyuan $M_{\mathrm{S}} 8.5$ earthquake in Ningxia) and ended on January 7, 1937 (Alan Lake $M_{\mathrm{S}} 7.5$ earthquake in Qinghai); the second was from March 17, 1947 (Darlag, Qinghai, $M_{\mathrm{S}} 7.7$ earthquake) to April 14, 1955 (Kangding, Sichuan, $M_{\mathrm{S}} 7.5$ earthquake); the third started on January 5, 1970 (Tonghai, Yunnan, $M_{\mathrm{S}} 7.8$ event) and ended on August 23, 1976 (Pingwu, Sichuan, $M_{\mathrm{S}} 7.2$ event); the fourth was from the November 6, 1988 (Lancang, Yunnan, $M_{\mathrm{S}} 7.4$ earthquake) to February 3, 1996 (Lijiang, Yunnan, $M_{\mathrm{S}} 7.0$ earthquake). Now the May 12, 2008 (Wenchuan, Sichuan, $M_{\mathrm{S}} 8.0$ earthquake) is the beginning of a new active phase; it may last 7-17 years, averagely about ten years. In this active phase, there would be four to seven (six on average) events with $M_{\mathrm{S}} \geq 7.0$ (see Table 2 for details).

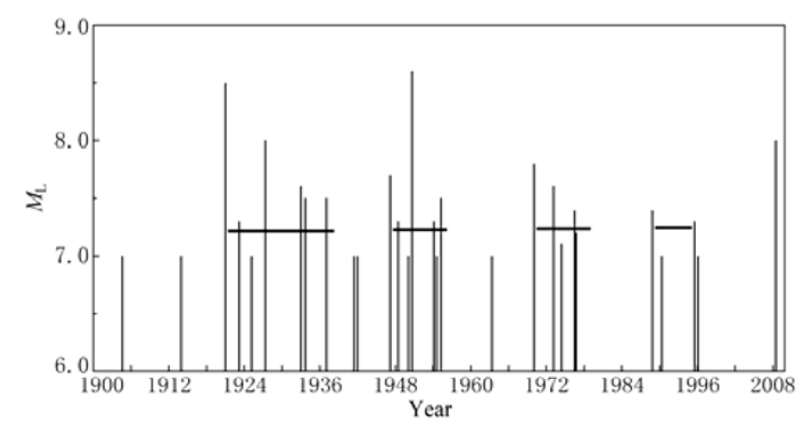

Figure $2 M$ - $t$ diagram of $M_{\mathrm{S}} \geq 7.0$ earthquakes for the North-South seismic belt. The horizontal thick lines denote four active phases for $M_{\mathrm{S}} \geq 7.0$ earthquakes.

Table 2 Statistics of $M_{\mathrm{S}} \geq 7.0$ earthquakes on the North-South seismic belt

\begin{tabular}{|c|c|c|c|c|c|c|c|c|}
\hline \multirow{2}{*}{ No. } & \multicolumn{3}{|c|}{ Beginning earthquake of the active phase } & \multicolumn{3}{|c|}{ Ending earthquake of the active phase } & \multirow{2}{*}{$\begin{array}{c}\text { Active time } \\
/ \mathrm{a}\end{array}$} & \multirow{2}{*}{$\begin{array}{l}\text { Number of } \\
\text { earthquakes }\end{array}$} \\
\hline & a-mo-d & Location & $M_{\mathrm{S}}$ & a-mo-d & Location & $M_{\mathrm{S}}$ & & \\
\hline 1 & $1920-12-16$ & Haiyuan, Ningxia & 8.5 & 1937-01-07 & Alan Lake, Qinghai & 7.5 & 17 & 7 \\
\hline 2 & $1947-03-17$ & Darlag, Qinghai & 7.7 & 1955-04-14 & Kangding, Sichuan & 7.5 & 8 & 7 \\
\hline 3 & $1970-01-05$ & Tonghai, Yunnan & 7.8 & $1976-08-23$ & Pingwu, Sichuan & 7.2 & 7 & 5 \\
\hline 4 & 1988-11-06 & Lancang, Yunnan & 7.4 & 1996-02-03 & Lijiang, Yunnan & 7.0 & 8 & 4 \\
\hline 5 & $2008-05-12$ & Wenchuan, Sichuan & 8.0 & & $?$ & & $7-17$ & $4-7$ \\
\hline
\end{tabular}




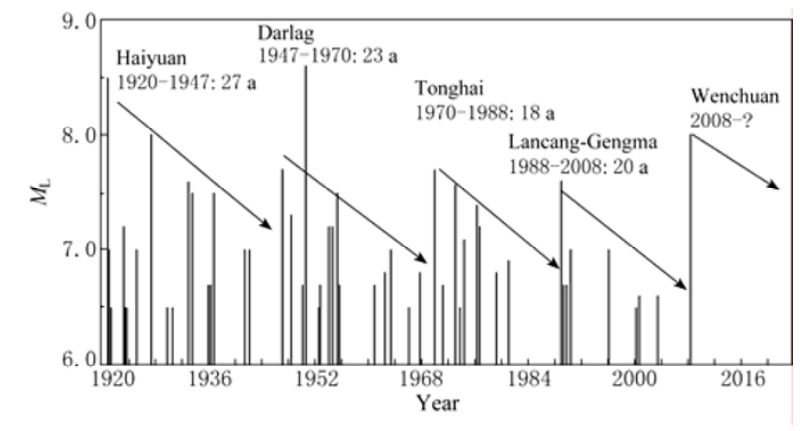

Figure 3 Active-quiet alternative cycles of $M_{\mathrm{S}} \geq 6.5$ earthquakes on the North-South seismic belt.

Earthquakes with $M_{\mathrm{S}} \geq 6.5$ from the area of $20^{\circ} \mathrm{N}-$ $45^{\circ} \mathrm{N}, 95^{\circ} \mathrm{E}-107^{\circ} \mathrm{E}$ are given in Figure 3 and Table 3. It is obvious from the Figure 3 that $M_{\mathrm{S}} \geq 6.5$ earthquakes are characterized by active-quiet alternative cycles. Earthquakes occurred at the turn point from quiet phase to active phase are of fairly high magnitude, larger than $M_{\mathrm{S}} 7.7$, except for one with magnitude of $M_{\mathrm{S}} 7.4$. The
Wenchuan $M_{\mathrm{S}} 8.0$ earthquake started the beginning of the current (the fifth) cycle, which is consistent with the estimate of magnitude and time. The cycle period is estimated to last 18-27 years (22 years on the average).

On the North-South seismic belt, earthquakes with $M_{\mathrm{S}} \geq 7.0$ and $M_{\mathrm{S}} \geq 6.5$ are of obvious regularities, but why did we predict the level of activity too low before the Wenchuan earthquake? The predominated viewpoint in that time is that we thought a new cycle should come after a still longer quiet phase, so that $M_{\mathrm{S}} \geq 7.0$ earthquakes would not occur right now. In fact, at that time, the cycle starting on November 6, 1988 (Lancang $M_{\mathrm{S}} 7.4$ earthquake, Yunnan) had lasted 20 years. It is seven years shorter than that of the first cycle and three years shorter than that of the second cycle, but two years longer than that of the third cycle. Therefore, it is very risky to make the judgment that the quiet phase may sustain further. This is a profound lesson need be drawn (see Table 3).

Table 3 Statistics of $M_{\mathrm{S}} \geq 6.5$ earthquakes on the North-South seismic belt

\begin{tabular}{|c|c|c|c|c|c|}
\hline \multirow{2}{*}{ No. } & \multicolumn{3}{|c|}{ Beginning earthquake of the cycle } & \multirow{2}{*}{$\begin{array}{c}\text { Cycle duration } \\
\text { /a }\end{array}$} & \multirow{2}{*}{$\begin{array}{c}\text { Number of earthquakes } \\
\text { with } M_{\mathrm{S}} \geq 7.0\end{array}$} \\
\hline & a-mo-d & Location & $M_{\mathrm{S}}$ & & \\
\hline 1 & $1920-12-16$ & Haiyuan, Ningxia & 8.5 & 27 & 9 \\
\hline 2 & $1947-03-17$ & Darlag, Qinghai & 7.7 & 23 & 8 \\
\hline 3 & 1970-01-05 & Tonghai, Yunnan & 7.8 & 18 & 5 \\
\hline 4 & 1988-11-06 & Lancang, Yunnan & 7.4 & 20 & 4 \\
\hline 5 & $2008-05-12$ & Wenchuan, Sichuan & 8.0 & $18-27$ & $4-9$ \\
\hline
\end{tabular}

\subsection{Rhythmic occurred pattern for big earthquakes}

The strong earthquakes in Chinese mainland have a rhythmic pattern (i.e., each circulation experiences the same time interval) of 25 years in occurrence time (Gao et al, 2002). For example, the 1902 Artux $M_{\mathrm{S}} 8.3$ earthquake of Xinjiang, and 1906 Shawan $M_{\mathrm{S}} 8.0$ earthquake of Xinjiang are the two largest earthquakes in the first active phase. Inferred from such a rhythmic occurred pattern, twenty-five years after 1902 (Artux $M_{\mathrm{S}} 8.3$ earthquake) is the year of 1927, in which the Gulang $M_{\mathrm{S}} 8.0$ earthquake occurred. 1906 (Shawan $M_{\mathrm{S}} 8.0$ earthquake) plus 25 years is the year of 1931, in which the Fuyun $M_{\mathrm{S}} 8.0$ earthquake happened. Twenty-five years after 1927 (Gulang $M_{\mathrm{S}} 8.0$ earthquake) is the year of 1952 and around this year there were Zayu $M_{\mathrm{S}} 8.6$ (1950, Tibet) and Damxung $M_{\mathrm{S}} 8.0$ (1951, Tibet) earthquakes. Such a rhythmic occurred pattern is continued, for example, twenty-five years after 1931 is the year of 1956 and a $M_{\mathrm{S}} 8.3$ earthquake occurred in 1957 in Mon- golia, which is closely neighbor to Chinese mainland. Another example is that twenty-five years after 1951 is the year of 1976, in which the Tangshan $M_{\mathrm{S}} 7.8$ earthquake occurred; twenty-five years after 1976 is the year of 2001, in which the Kunlun mountain $M_{\mathrm{S}} 8.1$ earthquake occurred (see Table 4a for details).

The rhythmic occurred pattern for huge earthquakes of Chinese mainland is grouped. Let us now analyze the Wenchuan $M_{\mathrm{S}} 8.0$ earthquake by the aid of this pattern. Twenty-five years before 2008 is the year of 1983 , in which the Wuqia $M_{\mathrm{S}} 6.8$ earthquake occurred, even though it does not meet the condition of great earthquakes. Twenty-five years before 1983 is the year of 1958 and indeed a $M_{\mathrm{S}} 8.3$ earthquake happened in Mongolia on January 4, 1957. Tracing back by 25 years, the Fuyun $M_{\mathrm{S}} 8.0$ earthquake occurred on August 11, 1931. Tracing back by another 25 years, the Shawan $M_{\mathrm{S}} 8.0$ earthquake took place on December 23, 1906 (see Table $4 \mathrm{~b}$ for detailed statistic). 
Table 4a The rhythm occurred patterns of huge earthquakes in Chinese mainland

\begin{tabular}{|c|c|c|c|c|c|c|c|}
\hline \multirow{2}{*}{ No. } & \multicolumn{3}{|c|}{ Rhythmic earthquake 1} & \multicolumn{3}{|c|}{ Rhythmic earthquake 2} & \multirow{2}{*}{ Time separation } \\
\hline & a-mo-d & Location & $M_{\mathrm{S}}$ & a-mo-d & Location & $M_{\mathrm{S}}$ & \\
\hline 1 & $1902-08-22$ & Artux, Xinjiang & 8.3 & $1927-05-23$ & Gulang, Gansu & 8.0 & 24 years and 9 months \\
\hline 2 & $1927-05-23$ & Gulang, Gansu & 8.0 & $1951-11-18$ & Damxung, Tibet & 8.0 & 24 years and 6 months \\
\hline 3 & $1951-11-18$ & Damxung, Xizang & 8.0 & $1976-07-28$ & Tangshan, Hebei & 7.8 & 24 years and 8 months \\
\hline 4 & $1976-07-28$ & Tangshan, Hebei & 7.8 & 2001-11-14 & Kunlun mountain, Qinghai & 8.1 & 25 years and 4 months \\
\hline 5 & 2001-11-14 & Kunlun mountain, Qinghai & 8.1 & & $?$ & & $24-26$ years \\
\hline \multicolumn{8}{|l|}{ Table 4b } \\
\hline \multirow{2}{*}{ No. } & \multicolumn{3}{|c|}{ Rhythmic earthquake 1} & \multicolumn{3}{|c|}{ Rhythmic earthquake 2} & \multirow{2}{*}{ Time separation } \\
\hline & a-mo-d & Location & $M_{\mathrm{S}}$ & a-mo-d & Location & $M_{\mathrm{S}}$ & \\
\hline 1 & $1906-12-23$ & Shawan, Xinjiang & 8.0 & 1931-08-11 & Fuyun, Xinjiang & 8.0 & 24 years and 8 months \\
\hline 2 & $1931-08-11$ & Fuyun, Xinjiang & 8.0 & $1957-12-04$ & Mongolia & 8.3 & 26 years and 3 months \\
\hline 3 & $1957-12-04$ & Mongolia & 8.3 & $1983-02-13$ & Wuqia, Xinjiang & 6.8 & 25 years and 2 months \\
\hline 4 & $1983-02-13$ & Wuqia, Xinjiang & 6.8 & 2008-05-12 & Wenchuan, Sichuan & 8.0 & 25 years and 3 months \\
\hline
\end{tabular}

Note: The Wuqia M6.8 earthquake is inconsistent with the conditions of huge earthquakes.

\section{Spatial characteristics of strong earthquakes in China}

\subsection{Spatial distribution of large earthquakes in the western China and adjacent areas}

In the above section we investigated time characteristics of strong earthquake activity of China, it is also important for us to study the spatial characteristics of strong earthquake activity so as to fully understand the spatio-temporal occurred patterns for large earthquakes of China. The nine $M_{\mathrm{S}} \geq 8.0$ earthquakes in Chinese mainland since 1900 can be cataloged into four groups according to their occurrence time; and the $M_{\mathrm{S}} \geq 8.0$ earthquakes in each group are correlated with the geological structures in space. The first group includes the Artux $M_{\mathrm{S}} 8.3$ (1902, Xinjiang) and the Shawan $M_{\mathrm{S}} 8.0$ (1906, Xinjiang) earthquakes, which are both located in the Tianshan seismic belt. The Artux $M_{\mathrm{S}} 8.3$ earthquake is located on the south boundary of the Tianshan active block, while the Shawan $M_{\mathrm{S}} 8.0$ earthquake is located on the north boundary of that block. The second group consists of the Haiyuan $M_{\mathrm{S}} 8.5$ (1920, Ningxia), the Gulang $M_{\mathrm{S}} 8.0$ (1927, Gansu) and the Fuyun $M_{\mathrm{S}} 8.0$ (1931, Xinjiang) earthquakes; they are located at the borders between Alxa active block and Qilian, Tarim, Junggar active blocks, respectively. The third group includes the Zayu $M_{\mathrm{S}} 8.6$ (1950, Tibet) and the Damxung $M_{\mathrm{S}} 8.0$ (1951, Tibet) earthquakes; they are located on the borders between the Lhasa active block, Himalayan active block and Qiangtang active block. The fourth group consists of the Kunlun mountain $M_{\mathrm{S}} 8.1$ (2001, western Kunlun mountain pass) and the Wenchuan $M_{\mathrm{S}} 8.0$ (2008, Sichuan) earthquakes; they are located on the borders between the Kunlun, Qaidam and Yangtze active blocks, as shown in Figure 4 (Zhang et al, 2004).

After the western Kunlun mountain pass earthquake (on November 14, 2001), some researchers classified the China-Russia-Mongolia $M_{\mathrm{S}} 7.9$ earthquake (on October $27,2003)$ as one of grouped $M_{\mathrm{S}} 8.0$ earthquakes. However, the two events are located in different geological blocks which are far apart in spatial correlation and can hardly be considered as a new grouped earthquake. At that time, some researchers classified the Mani $M_{\mathrm{S}} 7.5$ (on November 8, 1997, Tibet) and the Kunlun mountain $M_{\mathrm{S}} 8.1$ (on November 14, 2001) earthquakes as the above same group. Such a classification resolved the problem of inconsistency in structure; but the spatiotemporal features of $M_{\mathrm{S}} 8.0$ earthquakes can not be explained satisfactorily by the Mani $M_{\mathrm{S}} 7.5$ earthquake, which in magnitude is much lower than $M_{\mathrm{S}} 8.0$. However, the Wenchuan $M_{\mathrm{S}} 8.0$ earthquake can well explain the grouping characteristics of $M_{\mathrm{S}} 8.0$ earthquakes both in temporal and spatial pattern.

\subsection{Strong earthquake activities in the second arc fault zone and the Wenchuan large earthquake}

Zhang et al (2003) considered that the west Kunlun-A'nyemaqen arc fault zone (the second arc fault zone) is the boundary belt of $M_{\mathrm{S}} \geq 7.0$ earthquake in Chinese mainland. According to Xu et al (2001), in the east Kunlun-Qiangtang lithospheric structure, the crustal thickness reduces from $70-75 \mathrm{~km}$ in the south to $55-60$ $\mathrm{km}$ in the north. The crust is of layered structure consisting of interfaces of alternative high- and low-velocity layers with lenticular low-velocity layer in the mid-crust of the east section. The discontinuities of the lithospheric structure show that there are three major lithospheric shear faults at the depth of $150-250 \mathrm{~km}$ on 


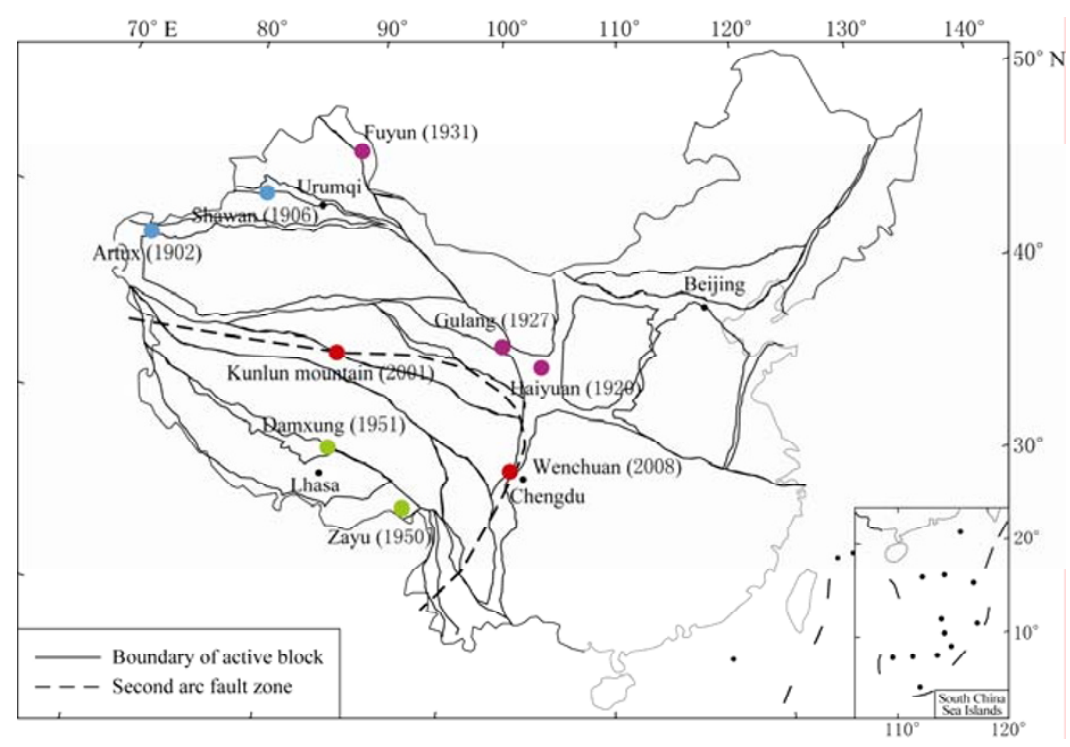

Figure 4 Distribution of $M_{\mathrm{S}} \geq 8.0$ earthquakes in Chinese mainland and its relation with active blocks.

block boundaries and interior; they are the South Kunlun-A'nyemaqen, Jinshajiang and Xianshuihe lithospheric shear faults. It is inferred that an eastward extrusion exists in the north of the Qinghai-Tibet plateau. To a certain extent, these results can give a geological and geophysical background for the tectonic implication and spatial settlement of the second arc fault zone.

The focal depth distribution, focal mechanism distribution and current plate movement from the GPS observation are jointly incorporated to probe into their characteristics, which are compared with the spatial distribution of first- and second-order active blocks and their boundaries. The results show that it is possible to determine the position of the second arc fault zone in Chinese mainland. It starts in the west at the juncture of the Kunlun active block, Tianshan active block and Tarim active block, extends eastward along the north boundary of Kunlun active block; that is, it stretches from the west Kunlun fault zone to Hoh Sai Hu-Maqu fault zone, then extends southward through the boundaries of the Kunlun active block, Sichuan-Yunnan active block, and South China active block (Zhang, 2006). But the Wenchuan $M_{\mathrm{S}} 8.0$ earthquake took place just on the boundary between the Sichuan-Yunnan and the South China active blocks. It is a typical huge earthquake that occurred on the second arc fault zone and it locates at the section where the fault zone turns their orientation from EW to NS (see Figure 5 for details).

Started by the Lancang $M_{\mathrm{S}} 7.4$ and the Gengma $M_{\mathrm{S}} 7.2$ (on November 6, 1988 in Yunnan), the activity of $M_{\mathrm{S}} \geq 7.0$ earthquakes in Chinese mainland entered a new clustered active phase; since then, ten $M_{\mathrm{S}} \geq 7.0$ earthquakes have occurred so far (see Table 5). It is very obvious that these earthquakes are distributed along the second arc fault zone (roughly in the range of $99^{\circ} \mathrm{E}-$ $103^{\circ} \mathrm{E}, 35^{\circ} \mathrm{N}-36^{\circ} \mathrm{N}$, see Figure 5).

Table 5 The $M_{\mathrm{S}} \geq 7.0$ earthquakes in the western Chinese mainland since 1988

\begin{tabular}{|c|c|c|c|c|c|}
\hline No. & $\begin{array}{c}\text { Occurrence time } \\
\text { a-mo-d }\end{array}$ & Lat. $/{ }^{\circ} \mathrm{N}$ & Long. $/{ }^{\circ} \mathrm{E}$ & $M$ & Site \\
\hline 1 & 1988-11-06 & 23.16 & 99.50 & 7.4 & Lancang, Yunnan \\
\hline 2 & 1988-11-06 & 22.92 & 99.79 & 7.2 & Gengma, Yunnan \\
\hline 3 & 1990-04-26 & 36.06 & 100.33 & 7.0 & Gonghe, Qinghai \\
\hline 4 & $1995-05-12$ & 22.00 & 99.30 & 7.3 & Menglian, Yunnan \\
\hline 5 & 1996-02-03 & 27.20 & 100.30 & 7.0 & Lijiang, Yunnan \\
\hline 6 & 1996-11-19 & 35.20 & 78.00 & 7.1 & Karakorum, Xinjiang \\
\hline 7 & 1997-11-08 & 35.20 & 87.30 & 7.5 & Mani, Tibet \\
\hline 8 & 2001-11-14 & 36.20 & 90.90 & 8.1 & Kunlun mountain, Qinghai \\
\hline 9 & 2008-03-21 & 35.60 & 81.00 & 7.3 & Yutian, Xinjiang \\
\hline 10 & $2008-05-12$ & 30.95 & 103.40 & 8.0 & Wenchuan, Sichuan \\
\hline
\end{tabular}




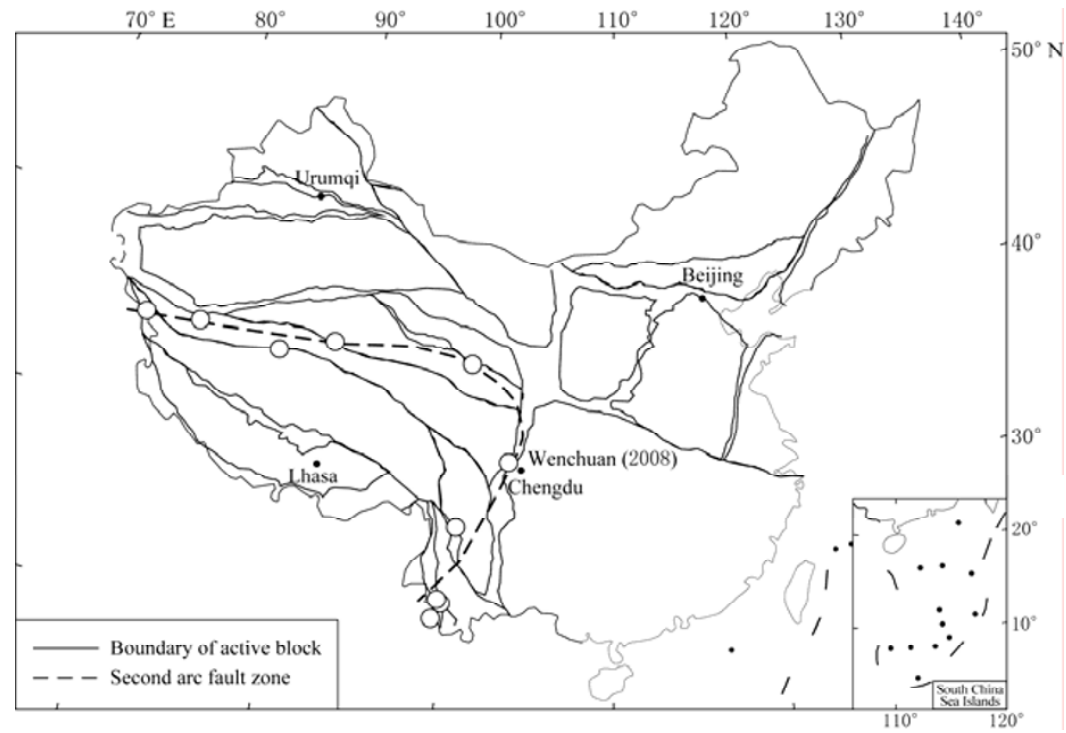

Figure 5 Relation between $M_{\mathrm{S}} \geq 7.0$ earthquakes in the western Chinese mainland since 1988 and the location of second arc fault zone.

\section{Spatio-temporal evolution character-} istics of strong earthquake activities in Chinese mainland versus the Wenchuan large earthquake

4.1 Spatio-temporal migration patterns of strong earthquakes on the North-South seismic belt

The $M_{\mathrm{S}} \geq 7.0$ earthquakes on the North-South seismic belt have stepwise migration patterns. Generally, the activity of $M_{\mathrm{S}} \geq 7.0$ earthquakes begins in Yunnan and adjacent areas in the south section of the North-South seismic belt; then the activity migrates progressively from south to the middle of the belt step by step, and finally arrives at the north section of the belt. But, generally the next group migration starts during the former group northward migration rather than after it (see Figure 6 for details). For example, the Gonghe $M_{\mathrm{S}} 7.0$ earthquake (on April 26, 1990, Qinghai) is the one that ended the third northward migration; while the fourth migration already started by the Lancang $M_{\mathrm{S}} 7.4$ and Gengma $M_{\mathrm{S}} 7.2$ earthquakes (on November 6, 1988, Yunnan). Now the fourth group has migrated into the central part of the belt, therefore, it is very likely it would move to its north or south areas in the next step.

\subsection{Long-term activities of active blocks correlated} to the Wenchuan earthquake

The Wenchuan $M_{\mathrm{S}} 8.0$ earthquake took place on the boundary between the Bayan Har active block and South China active block. It is adjacent to the Qaidam

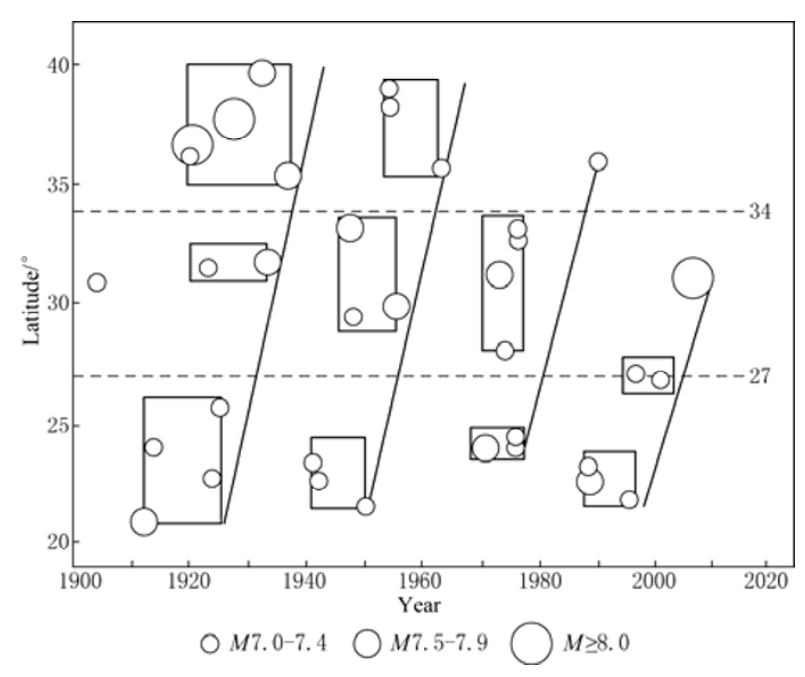

Figure 6 The spatio-temporal migration of strong earthquakes on the North-South seismic belt since 1900 .

active block in the north and Qiangtang active block and Sichuan-Yunnan rhombic block in the south. To discuss the relation between long-term activities of active blocks and Wenchuan earthquake, we select the $M_{\mathrm{S}} \geq 5.0$ earthquakes since 1900 , strictly within or at the boundaries of these active blocks. We investigated the seismic speeding-up features of these second-order active blocks by using the routine methods of the cumulative seismic frequency and energy creep curve. The results show that the Bayan Har active block, in which the Wenchuan $M_{\mathrm{S}} 8.0$ earthquake took place, did not show obvious seismic accelerated features both in frequency and en- 
ergy, but the Qaidam active block (adjacent to Bayan Har active block in the north), the Qiangtang active block and the Sichuan-Yunnan rhombic block (adjacent to Bayan Har active block in the south) did display obvious accelerated features (see Figures 7 and 8). Figure 7 gives the distribution of active blocks and $M_{\mathrm{S}} \geq 5.0$ earthquakes since 1900 in Chinese mainland. Figure 8 gives the cumulative frequency curves and the energy creep curves of the Bayan Har active block and adjacent active blocks. The results show that the Bayan Har active block has no obvious seismic speeding-up features. To further explain this, we can see from Figure 9 that

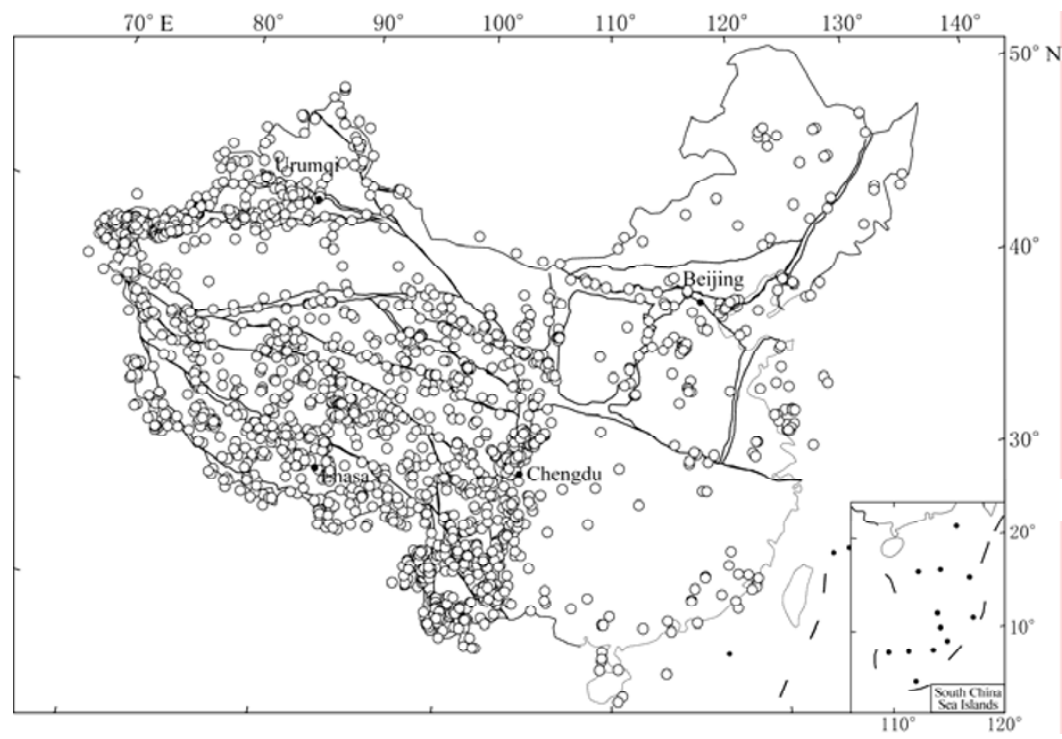

Figure 7 Distribution of active blocks and $M_{\mathrm{S}} \geq 5.0$ earthquakes since 1900 in Chinese mainland.
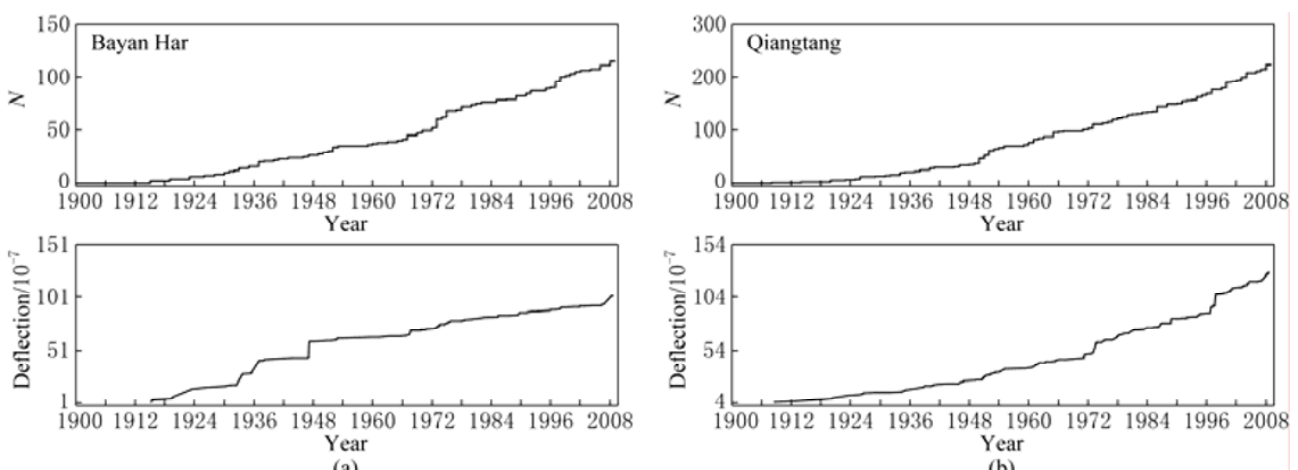

(a)
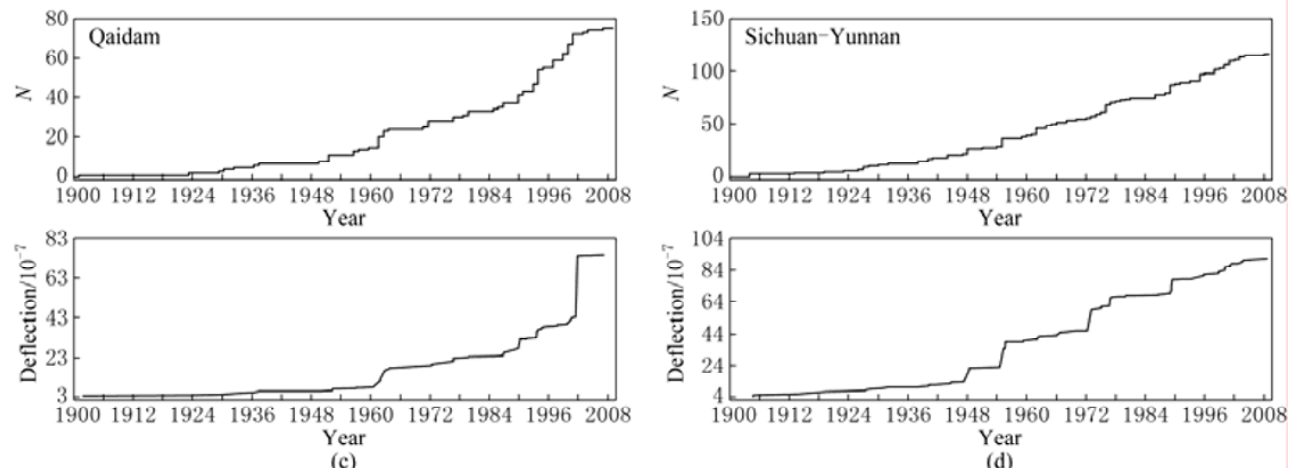

(c)

Figure 8 The seismic accelerating features of Bayan Har active block (a), Qiangtang active block (b), Qaidam active block (c) and Sichuan-Yunnan rhombic block (d). In each diagram, upper curves represent cumulative frequency $(N)$, lower ones represent creep release. 


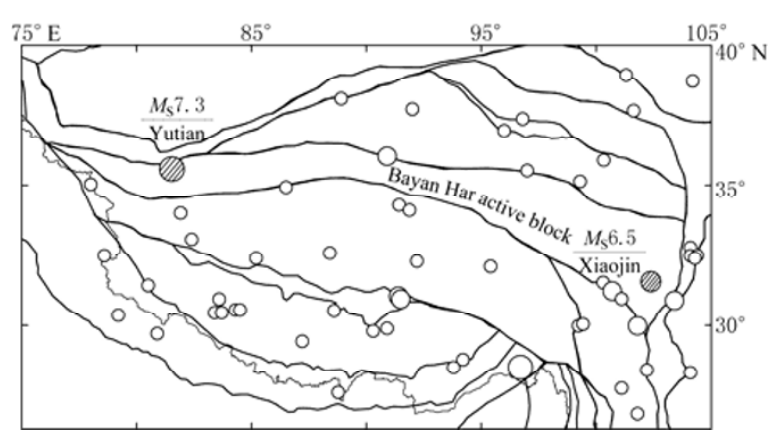

Figure 9 Distribution of $M \geq 6.5$ earthquakes in the Bayan Har and its adjacent active block since 1950. denote the Yutian $M_{\mathrm{S}} 7.3$ earthquake in Xinjiang on March 21, 2008 and the Xiaojin $M_{\mathrm{S}} 6.6$ earthquake in Sichuan on September 22, 1989.

there have been only two $M_{\mathrm{S}} \geq 5.0$ earthquakes occurred within the Bayan Har active block since 1950; they are the Xiaojin $M_{\mathrm{S}} 6.6$ earthquake (1989) and the Yutian $M_{\mathrm{S}} 7.3$ earthquake (2008), which were both located near the boundaries of active blocks. Beside these two earthquakes, there were no $M \geq 6.5$ earthquakes within this active block. In contrast, $M_{\mathrm{S}} \geq 6.5$ earthquakes were more active within the Qiangtang and the Qaidam blocks. The Bayan Har active block in a strict sense shows no obvious seismic accelerating features. We try to study its seismic accelerating features if its boundary range is slightly enlarged (see Figure 10). In Figure 10, some seismic speeding-up features are found, which indicates that the Bayan Har active block is more stable in its interior, but more active along its outer boundary zone and adjacent active blocks.

Figures $11 \mathrm{a}-\mathrm{c}$ separately show the pre-seismic, co-seismic and post-seismic GPS variations (horizontal movement) of November 14, 2001 Kunlun mountain $M_{\mathrm{S}} 8.1$ earthquake. It can be seen that the Bayan Har active block had relatively large eastward but slightly southwardly movement, but the Qaidam active block only had a small westward movement; while, the Qiangtang active block had a little movement when the earthquake happened. Two $M_{\mathrm{S}} 6.0$ strong aftershock swarms were triggered after the main shock, one was located in Delingha of Qaidam active block and the other was located in Baingoin of Qiangtang active block. This seems to show that the Bayan Har active block moved eastward by slightly south steadily and quickly, and the active blocks adjacent to it adjusted dramatically. The GPS data show that the Bayan Har active block moved eastward by south steadily at a high speed after the Kunlun mountain $M_{\mathrm{S}} 8.1$ earthquake (see Figure 11c).
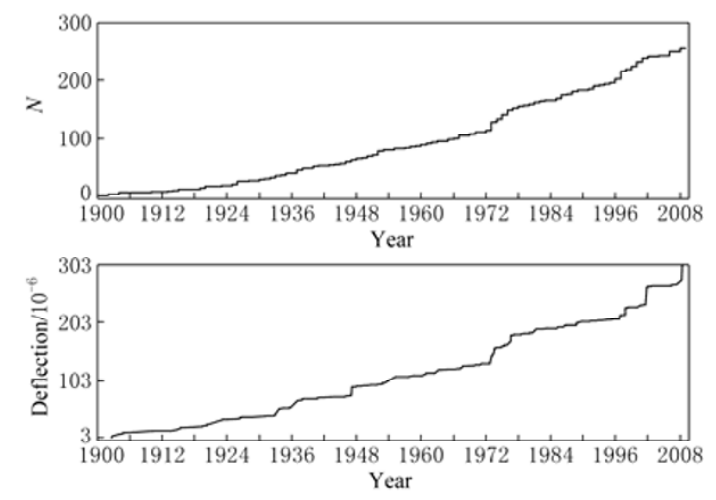

Figure 10 Seismic speeding-up features of enlarged Bayan Har active block. Upper panel is curve of cumulative frequency $(N)$; bottom panel is curve of energy creep release.

Such a mode of movement formed one of the dynamic conditions for the preparation of the Wenchuan $M_{\mathrm{S}} 8.0$ earthquake. When the Bayan Har active block in a whole made a steady movement toward to the east by slightly south, it was blocked by the stable Sichuan basin. In that case, there should be large amounts of stress and energy accumulated homogeneously on large scale along the Longmenshan fault zone (from Wenchuan of Sichuan to Ningqiang of Shaanxi), which is the boundary zone between the Bayan Har active block and rigid Sichuan basin extending perpendicularly to the direction of the above movement. Such a mode of motion is the most important kinematics condition that finally trigged the Wenchuan $M_{\mathrm{S}} 8.0$ earthquake.

\subsection{Discussion on the $m$ echanism of the second arc fault zone}

The focal mechanism solutions of $M_{\mathrm{S}} \geq 5.0$ earthquakes in Chinese mainland and adjacent areas $(\mathrm{Xu}$, 2001; Li and Qin, 1994; England and Houseman, 1988) show that, fault activities are mainly normal faulting in the south, reversal faulting in the north, and strike-slip faulting in nearby areas of the second arc fault zone. The group velocity of Rayleigh waves and velocity of Pn waves were low in the south of the second arc fault zone, which may indicate that there was hot material uplifting underneath. The high group velocity of Rayleigh waves and high velocity of Pn waves in the north of the second arc fault zone were consistent with the distribution of basins (Zhu et al, 2002; Wang et al, 2003).

The NE-trending two-way squeeze caused by the northward push of Indian plate and the southward intrusion of Qaidam block supplied power source for stress accumulation in the epicentral region. The thickening of the weaker crust in the north of the Qinghai-Tibet plateau 

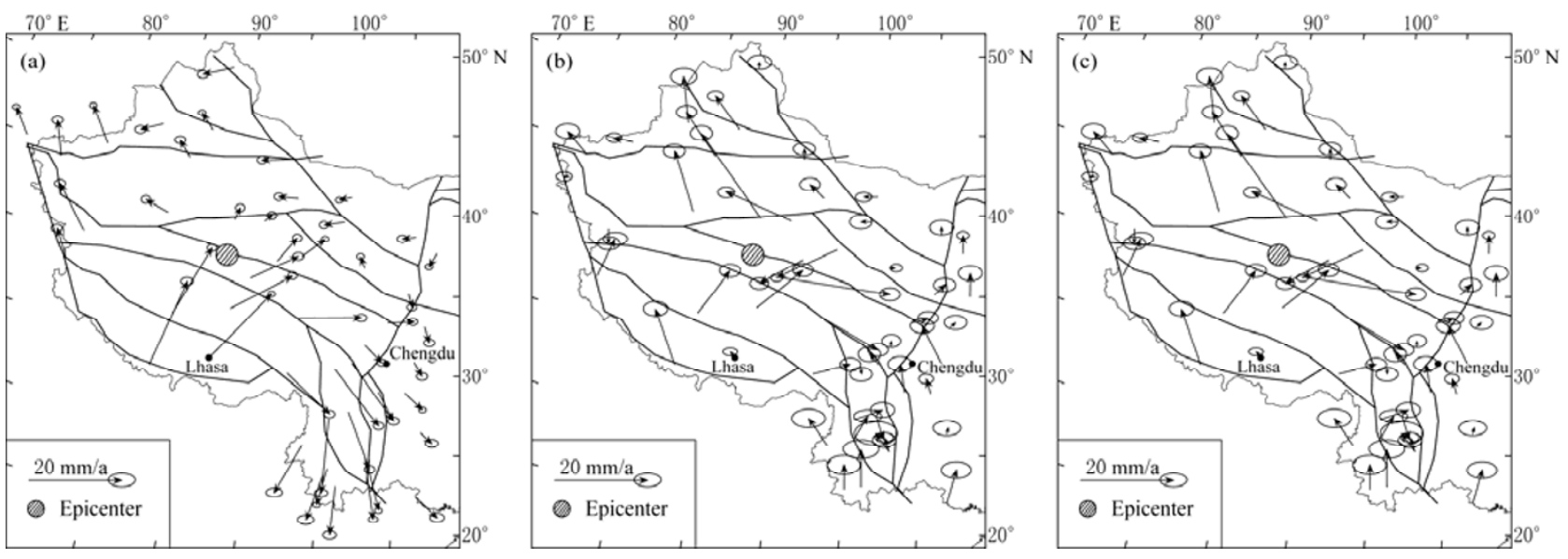

Figure 11 Horizontal movement observed by GPS before, during and after the Kunlun mountain $M_{\mathrm{S}} 8.1$ earthquake. (a) Preseismic deformation in 1998-2001; (b) Coseismic deformation in 2001-2002; (c) Postseismic deformation in 2003-2006.

has made the crustal thickness between east Kunlun and Qaidam change dramatically so that the regional horizontal stress for earthquake preparation was formed. The tilted Moho represents an unstable state. The low velocity layer in middle crust, which acts as a detachment surface, would transfer the residual stress of shortening deformation from deep to shallow crust. In this process, the creeping movement would cause stress concentration. The low velocity layer restricted the further downward extension of the seismogenic fault and also provided the condition for its strike-slip ( $\mathrm{Li}$ et al, 2004; Zhang and $\mathrm{Xu}, 1995)$.

Study of the focal depth distribution in Chinese mainland shows that $M_{\mathrm{S}} \geq 4.7$ earthquakes with focal depth of $\geq 30 \mathrm{~km}$ are dominated in the south of the second arc fault zone, mostly in the Qiangtang active block (see Figure 12 for details). Further study shows that the earthquakes with focal depth of $\geq 30 \mathrm{~km}$ and magnitude of $M_{\mathrm{S}} \geq 6.0$ all took place on the boundaries of active blocks and had the regularity of traversing active blocks. There are two banded seismic belts and one seismic zone. One belt extends from Zhongba to Pamir in western Qinghai-Tibet plateau with NEN direction; the other belt is from the central part of Qinghai-Tibet plateau to Altay, Xinjiang. The seismic zone is located in the Assam region in the east corner of Qinghai-Tibet plateau (see Figure 13 for details).

The distribution characteristics of earthquakes with

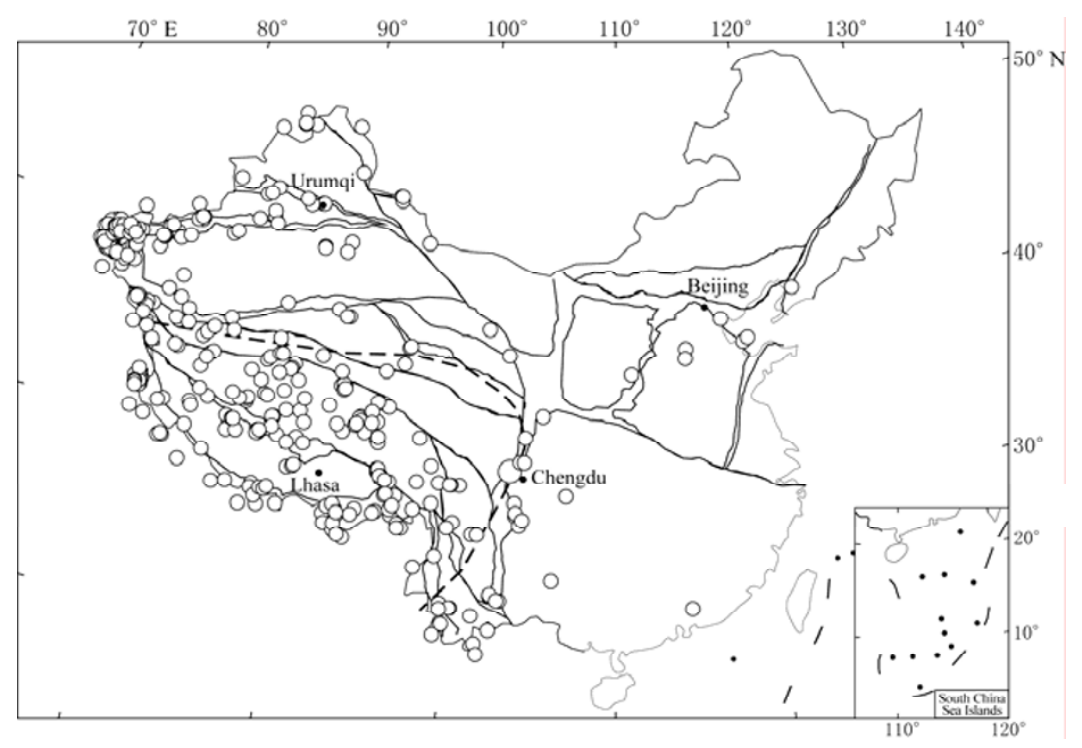

Figure 12 Distribution of $M_{\mathrm{S}} \geq 4.7$ earthquakes with focal depth of $\geq 30 \mathrm{~km}$ and the active blocks in Chinese mainland. 


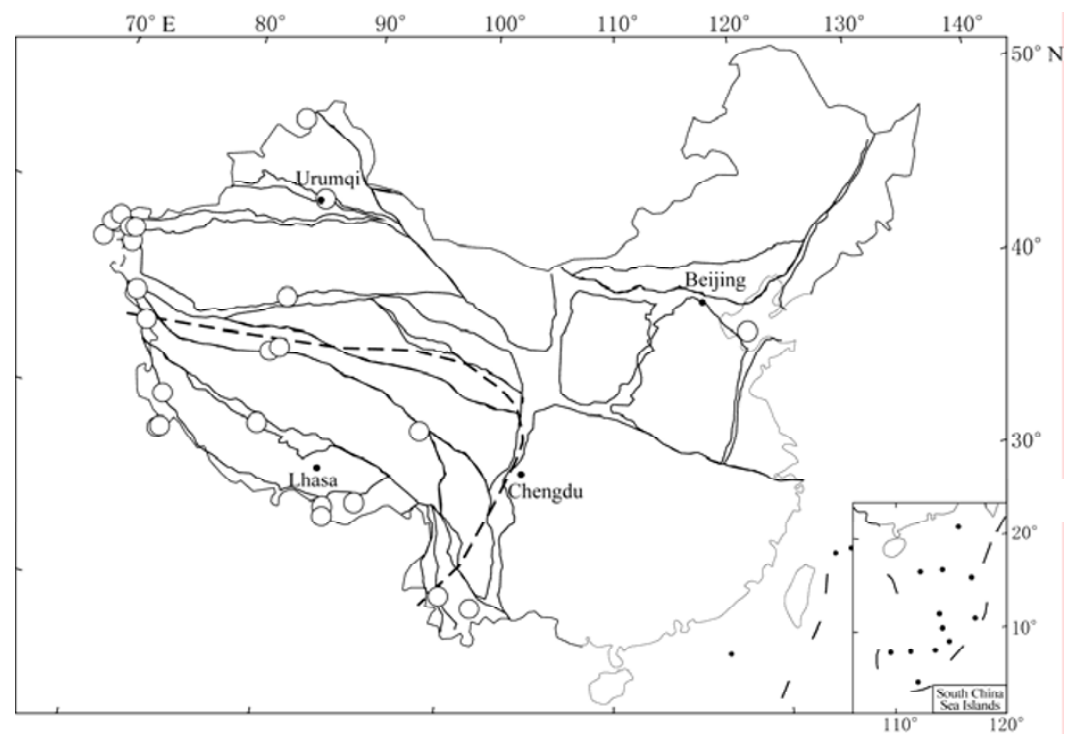

Figure 13 Distribution of $M \geq 6.0$ earthquakes with focal depth of $\geq 30 \mathrm{~km}$ and the active blocks in Chinese mainland.

focal depth of $0-15 \mathrm{~km}$ or $16-30 \mathrm{~km}$ or $\geq 30 \mathrm{~km}$ focal depths are further investigated, and the percentages of earthquakes of different types at each depth range are calculated. Statistical results are as follows: in $0-15 \mathrm{~km}$ depth range, thrust type earthquakes account for $68 \%$ of the total in the northern part of the second arc fault zone, which is doubled the corresponding natural probability (33\%) (Figure 14a). Normal fault earthquakes are mainly distributed in the southern part of the second arc fault zone, accounting for different percentages in different depth ranges, which are all higher than the corresponding natural probability $(33 \%)$. In the shallow crust $(0-15 \mathrm{~km})$ on the southern side of the second arc fault zone, the percentage of normal fault earthquakes is the highest. In contrast, on the southern side of the second arc fault zone, the percentage of normal fault earthquakes distributing below $30 \mathrm{~km}$ is $28 \%$, which is lower than the natural probability (Figure 14b). On the northern and southern sides of the second arc fault zone, the distribution percentages of strike-slip earthquakes are both higher than the natural probability (33\%). Strike-slip earthquakes on the northern side are mainly distributed at depth greater than $16 \mathrm{~km}$. Within 15-30 km depth range, earthquakes are all of strike-slip type, and most of them are located in the depth greater than $30 \mathrm{~km}$ (about 70\%). Strike-slip earthquakes on the south side of the second arc fault zone have basically approximated percentages in different depth ranges (Figure 14c) (Zhang, 2006).
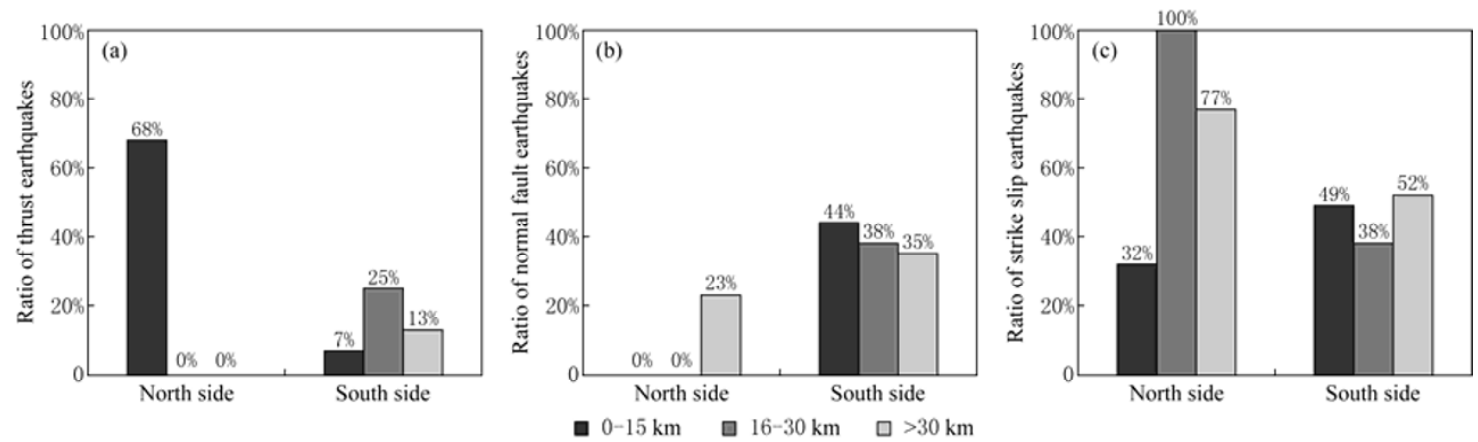

Figure 14 Distributions of thrust faulting (a), normal faulting (b) and strike-slip faulting (c) earthquakes in different depth ranges and characteristics of the second arc fault zone.

The second arc fault zone is the demarcation not only of earthquake types but also of focal depth distribution. In the north of the second arc fault zone, shallow thrust earthquakes account for a higher percentage of the total; while normal fault earthquakes generally make up a higher percentage in the south, especially in shallow crust. Perhaps this can be attributed to the different regional stresses on the northern and southern sides of 
Qinghai-Tibet block delineated by the second arc fault zone. The lower group velocity of Rayleigh waves and velocity of Pn waves on the southern side of the second arc fault zone are considered to be caused by hot material uplifting, which can also account for the higher percentage of normal fault earthquakes in this area.

\section{Discussion and conclusions}

The relation between the active-quiet characteristics of large earthquake activities in Chinese mainland and the Wenchuan $M_{\mathrm{S}} 8.0$ earthquake has been studied in this paper. The results show that the previous predicted annual seismic level of $M_{\mathrm{S}} 6.0-7.0$ in 2008 before the Wenchuan $M_{\mathrm{S}} 8.0$ earthquake did not fully consider the uncertainty of statistical method. In the North-South seismic belt, $M_{\mathrm{S}} \geq 7.0$ earthquakes have an alternative active quiet phase, and the Wenchuan $M_{\mathrm{S}} 8.0$ earthquake has started a new active phase, which is estimated to last about 10 -year with four to seven $M_{\mathrm{S}} \geq 7.0$ earthquakes to be happen. The temporal structure of strong earthquakes in Chinese mainland roughly have a 25-year rhythm, and the large earthquakes can be divided into two groups according to the above rhythm, that is that the Kunlun mountain $M_{\mathrm{S}} 8.1$ and the Wenchuan $M_{\mathrm{S}} 8.0$ earthquakes belong to the first and second group, respectively.

The spatial grouped characteristic of $M_{\mathrm{S}} 8.0$ earthquakes in Chinese mainland is obvious, and nine $M_{\mathrm{S}} \geq 8.0$ earthquakes since 1900 can be cataloged into four groups The fourth group earthquakes that have occurred so far are the Kunlun mountain $M_{\mathrm{S}} 8.1$ and the Wenchuan $M_{\mathrm{S}} 8.0$ earthquakes, which are located on the border between the Kunlun, Qaidam and Yangtze active blocks.

The Wenchuan $M_{\mathrm{S}} 8.0$ earthquake is closely related with the strong earthquake activity in the second arc fault zone that is located at where the second arc fault zone turns from EW to NS-trending. The activity of $M_{\mathrm{S}} \geq 7.0$ earthquakes in Chinese mainland has entered a new clustered active phase starting with the Lancang $M_{\mathrm{S}} 7.4$ and the Gengma $M_{\mathrm{S}} 7.2$ earthquakes (on November 6, 1988, Yunnan). Since then, there have been ten earthquakes with $M_{\mathrm{S}} \geq 7.0$ to occur. It is quite obvious that these earthquakes are distributed along the second arc fault zone.

The activity of $M_{\mathrm{S}} \geq 7.0$ earthquakes in the North-South seismic belt has the features of stepwise migration pattern. The northward migration of new group usually starts before the ending of northward migration for the former group. The next earthquake of the fourth group would move to the north or south part of the North-South seismic belt according to the past migration pattern.

Inside the Bayan Har active block where the Wenchuan $M_{\mathrm{S}} 8.0$ earthquake occurred, there is no evidence for seismic acceleration before the Wenchuan $M_{\mathrm{S}} 8.0$ earthquake. In contrast, the northern adjacent Qaidam active block and the southern adjacent Qiangtang active block and Sichuan-Yunnan rhombic block have showed obvious features of seismic acceleration. If the outer boundary of Bayan Har active block is enlarged, there would see some features for seismic acceleration. This means that it is more stable inside the Bayan Har active block, but more active at its outer boundary and adjacent active blocks.

In the southern part of the second arc fault zone, normal fault activities dominate; in the north, reversal faulting earthquakes prevail; and in nearby areas, strikeslip faulting earthquakes are most located. The group velocity of Rayleigh waves and velocity of Pn waves were low in the southern part of the second arc fault zone, so there might be hot material uplifting. The distribution of focal depths in Chinese mainland shows that earthquakes with focal depth lower than $30 \mathrm{~km}$ are concentrated in the southern part of the second arc fault zone, mostly located in Qiangtang active block. But earthquakes of higher magnitude are located on the boundaries of active blocks and the second arc fault zone is a boundary with deep material movement.

Acknowledgements The authors would like to express their thanks to Xiaoping Wang, Chaoying Bai and Jia Cheng for their help in the process of study, and also to the anonymous reviewers for their valuable suggestions.

\section{References}

Aktar M, Ozalaybey S, Ergin M, Karabulut H, Bouin M P, Tapirdamaz C, Bicmen F, Yoruk A and Bouchon M (2004). Spatial variation of aftershock activity across the rupture zone of the 17 August 1999 Izmit earthquake, Turkey (in active faulting and crustal deformation in the eastern Mediterranean region). Tectonophysics 391(1-4): 325-334.

Bouchon M, Campillo M and Cotton F (1998a). Stress field associated with the rupture of the 1992 Landers, California, earthquake and its implications concerning the fault strength at the onset of the earthquake. $J$ Geophys Res 103(B9): 21 091-21 097.

Bouchon M, Sekiguchi H, Irikura K and Iwata T (1998b). Some characteristics of the stress field of the 1995 Hyogo-ken Nanbu (Kobe) earthquake. $J$ Geophys Res 103(B10): 24 271-24 282.

Chao B F and Gross R S (2005). Did the 26 December 2004 Sumatra, Indonesia, earthquake disrupt the Earth's rotation as the mass media have said? Eos Trans AGU 86(1): doi:10.1029/2005EO010003.

Charles G B (2004). Comparing the November 2002 Denali and November 2001 Kunlun earthquakes. Bull Seism Soc Amer 94: 1 159-1 165.

Chen C, Rundle J B, Li H C, Holliday J R, Turcotte D L and Tiampo K F (2006). Critical point theory of earthquakes: Observation of correlated and cooperative behavior on earthquake fault systems. Geophys Res Lett 33: 
L18302, doi:10.1029/2006GL027323.

Chen Z L and Li Z X (2008). On the earthquake prediction (I) - Discussion about some experience and its basic point for earthquake prediction in China. Earthquake 28(1): 1-18 (in Chinese with English abstract).

Chen Z L and Li Z X (2009). Severe failure and important recognition: some thoughts on earthquake monitoring and prediction research due to the Wenchuan 8.0 earthquake. Earthquake 29(1): 182-191 (in Chinese with English abstract).

Dodge D A, Beroza G C and Ellsworth W L (1995). Foreshock sequence of the 1992 Landers, California, earthquake and its implications for earthquake nucleation. J Geophys Res 100(B6): 9 865-9 880.

England P C and Houseman G A (1988). The mechanics of the Tibetan Plateau. Phil Trans Roy Soc Lond A326: 301-320.

Frank K W, Duncan C A and Michael G (1994). Continuous measurements of crustal deformation for the 1992 Landers earthquake sequence. Bull Seism Soc Amer 84: 768-779.

Fu Z X and Cheng Y (1986). Some characteristics of recent episodic seismicity in the mainland of China. Earthquake (2): 28-35 (in Chinese with English abstract).

Gao X, Ding J H and Zhang X T (2002). New Method and Mechanism Research for the Medium-Term Strong Earthquakes Prediction. Department of Monitoring and Prediction, China Earthquake Administration, 151-155 (in Chinese).

Hauksson E (1994). State of stress from focal mechanisms before and after the 1992 Landers earthquake sequence. Bull Seism Soc Amer 84: 917-934.

Iio Y, Horiuchi S, Baris S, Çelik C, Kyomen J, Üçer B, Honkura Y and Isikara A M (2002). Aftershock distribution in the eastern part of the aftershock region of the 1999 Zmit, Turkey, earthquake. Bull Seism Soc Amer 92: 411-417.

Kondo H, Nakata T, Akhtar S S, Wesnousky S G, Sugito N, Kaneda H, Tsutsumi H, Khan A M, Khattak W and Kausar A B (2008). Long recurrence interval of faulting beyond the 2005 Kashmir earthquake around the northwestern margin of the Indo-Asian collision zone. Geology 36: 731-734.

Li H J and Qin J (1994). The focal mechanism and present stress field of Burma Arc and nearby. Acta Geoscientica Sinica 16(4): 463-471 (in Chinese with English abstract).

Li Q S, Peng S P, Gao R, Guan Y and Fan J Y (2004). Deep tectonic background of the $M_{\mathrm{S}} 8.1$ earthquake in the east Kunlun. Acta Geoscientica Sinica 25(1): 11-16 (in Chinese with English abstract).

Liu J, Guo T S, Yang L M, Su Y J and Li G (2009). Retrospection on the conclusions of earthquake tendency forecasts before the Wenchuan $M_{\mathrm{S}} 8.0$ earthquake. Earthquake 29(4): 40-52.

Liu J, Guo T S, Yang L M, Su Y J and Liu G P (2008). Follow-up forecast study on the exceeding long quiet of the earthquake with $M_{\mathrm{S}}>6$ in China mainland during 2005-2007. Journal of Seismological Research 31(4): 252-259 (in Chinese with English abstract).
Negishi H, Mori J, Sato T, Singh R, Kumar S and Hirata N (2002). Size and orientation of the fault plane for the 2001 Gujarat, India earthquake $\left(M_{\mathrm{W}} 7.7\right)$ from aftershock observations: A high stress drop event. Geophys Res Lett 29(20): 1949, doi:10.1029/2002GL015280.

Parsons T, Ji C and Kirby E (2008). Stress changes from the 2008 Wenchuan earthquake and increased hazard in the Sichuan basin. Nature 454: 509-510, doi:10.1038/nature07177.

Walker K T and Shearer P M (2009). Illuminating the near-sonic rupture velocities of the intracontinental Kokoxili $M_{\mathrm{W}} 7.8$ and Denali fault $M_{\mathrm{W}} 7.9$ strike-slip earthquakes with global $\mathrm{P}$ wave back projection imaging. $J$ Geophys Res 114: B02304, doi:10.1029/2008JB005738.

Wang S Y, Xu Z H and Pei S P (2003). Pn velocity variation beneath China mainland and deep structure background for major earthquake generation. Chinese J Geophys 46(6): 779-785 (in Chinese with English abstract).

Wiemer S and Wyss M (1994). Seismic quiescence before the Landers $(M=7.5)$ and big Bear $(M=6.5) 1992$ earthquakes. Bull Seism Soc Amer 84: 900-916.

$\mathrm{Xu}$ Z H (2001). A present-day tectonic stress map for eastern Asia region. Acta Seismologica Sinica 23(5): 492-501.

Xu Z Q, Yang J L, Jiang M, Yuan X C, Li H B, Xue G Q, Qian H and Yuan X $\mathrm{C}$ (2001). Lithosphere structure and lithosphere shear fault of the east Kunlun-Qiangtang area in the southern of Qinghai-Tibet Plateau. Science in China (Series D) 31(Suppl.): 1-7 (in Chinese with English abstract).

Zhang D N and Xu Z H (1995). Possible dynamics of normal fault earthquakes in the upper crust of the south part of the Qinghai-Xizang Plateau. Acta Seismologica Sinica 8(2): 233-239.

Zhang G M (1987). Rhythmicity research of strong earthquakes in Chinese continent. Seismology and Geology 9(2): 27-38 (in Chinese with English abstract).

Zhang G M, Ma H, Wang H and Li L (2004). Relation of strong earthquakes and active block in Chinese continent. Science in China (Series D) 34(7): 591-599 (in Chinese).

Zhang X D ed-in-chief (2006). Research on the Comprehensive Prediction for Strong Earthquake Short-term Prediction. Seismological Press, Beijing, 199-206 (in Chinese).

Zhang X D, Wang H M, Lü M M and Yu S R (2003). Discussion on the strong earthquake $\left(M_{\mathrm{S}} \geq 7.0\right)$ activity relating with the west Kunlun-A'nyemaqen second arc fault zone on the Chinese Continent. Earthquake Research in China 19(4): 400-406 (in Chinese with English abstract).

Zhao B, Wang M, Yu T, Wan W, Lei J, Liu L and Ning B (2008). Is an unusual large enhancement of ionospheric electron density linked with the 2008 great Wenchuan earthquake? J Geophys Res 113: A11304, doi:10.1029/ 2008JA013613.

Zhu L B, Xu Q G and Chen X F (2002). Group velocity of Rayleigh wave in Chinese continent and its adjacent seas. Chinese $J$ Geophys 45(4): 475-482 (in Chinese with English abstract). 